\title{
PANKARARU DO TOCANTINS: HISTÓRIA, LUTAS E IDENTIDADES DE UM POVO ESQUECIDO E SEM TERRA
}

\author{
ELVIO JUANITO MARQUES DE OLIVEIRA JÚNIOR ${ }^{1}$ \\ UFT, BRASIL
}

ANDRÉ DEMARCHI ${ }^{2}$

UFT, BRASIL

\begin{abstract}
RESUMO: O presente artigo é um estudo etnográfico sobre os povos Pankararu do Tocantins, que migraram para o estado há mais de 70 anos e são originários de Pernambuco. Na primeira parte é realizada uma revisão de literatura, intercalada com os relatos de indígenas sobre conflitos, organização e os principais rituais dos Pankararu. Na segunda parte, com uso dos métodos etnográficos, por meio de entrevistas, observações e informações coletadas no primeiro semestre de 2017, analisa-se o percurso histórico desse povo indígena no Tocantins, ora esquecido, ora apenas identificado como pertencente ao Estado. Além disso, será realizada uma breve discussão sobre a identidade cultural desse povo, que se produz entre transformações, redimensionamentos em meio a elementos simbólicos que os diferem, e ainda a incansável luta pela demarcação da terra indígena.
\end{abstract}

PALAVRAS-CHAVE: Pankararu; Tocantins; Identidade; História

ABSTRACT: This article is an ethnographic study of the people Pankararu of Tocantins, who migrated to the state for more than 70 years and originate from Pernambuco. In the early chapters is performed a review of the literature, interspersed with reports of indigenous peoples, on the emergence, conflicts, organization and the main rituals of pankararu. In a second moment, with use of methods of ethnography, through interviews, observations and information collected in the first half of 2017, it analyzes the historical journey in Tocantins of indigenous people, sometimes forgotten, sometimes only identified as belonging to the state. In addition, there will be a brief discussion about the cultural identity of this people, that permeates between transformations, scaling in simbologicos elements that differ, and even the tireless struggle for the demarcation of indigenous land.

KEYWORDS: Pankararu; Tocantins; Identity; History

\footnotetext{
${ }^{1}$ Mestre em Comunicação e Sociedade, pós-graduado em Ensino de Comunicação e Sociedade pela Universidade Federal do Tocantins (UFT) e Jornalista pela mesma Universidade. Pertence à comunidade Pankararu do Tocantins. E-mail: elviojornalista@gmail.com

${ }^{2}$ Professor e Pesquisador na Universidade Federal do Tocantins, onde leciona no curso de Ciências Sociais e no Programa de Pós-Graduação em Comunicação e Sociedade. É doutor em Antropologia Cultural pelo Programa de Pós-graduação em Sociologia e Antropologia (PPGSA) da Universidade Federal do Rio de Janeiro. É membro do Núcleo de Estudos e Assuntos Indígenas (NEAI) e tutor do grupo Pet Indígena Conectando Conhecimentos. E-mail: andredemarchi@gmail.com
} 
Espaço Ameríndio

\section{Apresentação}

Há algum tempo percebemos a necessidade de escrever sobre os Pankararu, especificamente um dos povos localizados no Estado do Tocantins. Ora desconhecidos, ora apenas identificados entre os povos indígenas do $\mathrm{Estado}^{3}$, seja pela sociedade ou pelo poder público. O povo Pankararu ${ }^{4}$ é originário do Estado de Pernambuco. Tal povo se configura como uma das comunidades indígenas brasileiras, as quais foram sendo reconhecidas, com o passar do tempo, como povos que vivem em meio à preservação de suas tradições e diante do constante contato e das imposições provocadas pela sociedade envolvente, principalmente após o período de colonização do Brasil. Muitos desses indígenas migraram para outros lugares do país, graças ao grande número de invasões, perseguições de posseiros e fazendeiros, até mesmo por buscarem melhores condições para sobreviverem, visto que o Nordeste sofria também com a escassez de água, comida e emprego. João Pacheco de Oliveira (1998) reforça que os indígenas desta região brasileira eram confundidos com sertanejos pobres e sem acesso à terra.

Entre os estados escolhidos por estes nativos indígenas estavam São Paulo, Mato Grosso e o norte goiano, que hoje é o Tocantins. Para melhor traçar a origem, história e anseios desses indígenas no Estado do Tocantins, é preciso se deslocar cerca de $250 \mathrm{~km}$ da capital Palmas com destino a duas cidades na região sudeste do estado: Gurupi e Figueirópolis. Nessas cidades é que habitam hoje os Pankararu do Tocantins.

A pesquisa surge da relação pessoal de um dos autores deste capítulo, Elvio Marques, com os Pankararu, já que pertence à comunidade Pankararu. Sua mãe é Pankararu, seu pai é gaúcho, tendo ele crescido, portanto, em meio a um processo de hibridização cultural ${ }^{5}$, relacionado à boa parte da história desses indígenas. A principal referência da família era o avô materno, Manoel Barros ou Manoel Pankararu (como era conhecido), que contava histórias, crenças e ensinamentos sobre seu povo. Outra referência importante é seu tio Genildo Pankararu, o mais importante dos representantes desse povo no Estado.

\section{Serra de muitas pontas e a história conflituosa dos Pankararu}

Entre a Serra Grande e a Serra da Borborema, nas proximidades do rio São Francisco, é onde surge e está grande parte desse povo e suas

\footnotetext{
${ }^{3}$ De acordo o Núcleo de Estudos e Assuntos Indígenas da UFT, os povos indígenas do Tocantins são os Apinajé, Avá-Canoeiros, Akwe-Xerente, Krahô, Krahô Kanela, Pankararu, além dos Javaé, Karajá e Xambioá, que formam o povo Iny. Disponível em $<$ http://www.uft.edu.br/neai/?page id=28 $>$ Acesso em 16 jun 2017.

${ }^{4}$ Até 2008, os Pankararu contabilizavam aproximadamente 5.880 indivíduos, divididos, principalmente, entre o sertão Pernambucano e São Paulo, de acordo com França (2008). Assim como na maioria das pesquisas, os Pankararu do Tocantins não são contabilizados ou simplesmente não são mencionados.

${ }^{5}$ Esse termo foi empregado no sentido de que as culturas estão envolvidas entre si e que nenhuma delas é única, todas são hibridas, heterogêneas (BURKE, 2016; HALL, 1992; BARTH, 1976).
} 
principais tradições, especificamente nos municípios de Tacaratu, Petrolândia e Jatobá, em Pernambuco. Os Pankararu eram "caçadores coletores, pescadores, criadores de gado, galinha, cabras e agricultores" (OLIVEIRA, 2016, p. 8). Nas fontes históricas dos séculos XVII e XVIII são nomeados como "Pancararu", "Brancararu", "Pancaru" ou "Caruru" (FRANÇA, 2008). Todavia, é impossível descrever a história dos indígenas do Nordeste sem relacioná-la com o período de colonização e as imposições dos não indígenas, como os europeus.

Assim, a história dos Pankararu remete às ações missionárias que incluíam "deslocamentos e aldeamentos forçados, impondo a convivência e a posterior indiferenciação de diversas etnias na região" (FRANÇA, 2008, p. 17). Prova disso, é que esses indígenas foram expulsos de suas terras e passaram a ser aldeados à margem do São Francisco por missionários jesuítas, franciscanos e capuchinhos, onde mais tarde formaram a aldeia conhecida como Brejo dos Padres ${ }^{6}$, no início do século XVII (FRANÇA, 2008; OLIVEIRA, 2016). O início dessa história foi descrito por Genildo Pankararu, 52 anos, um dos principais representantes dos Pankararu no Tocantins e que vive no centro de Gurupi. Por meio de entrevista, ele contou:

Nós éramos povos que já existiam em Pernambuco, às margens do São Francisco. Pankararu significa serra de muitas pontas, já que ficava entre as serras. Daí chegou o homem branco, principalmente os padres. E nós fomos aos poucos procurando lugar pra se refugiar. E os padres queriam nos catequizar de todo jeito. Mas os Pankararu prenderam eles, numa espécie de caverna. E por isso a grande aldeia tradicional ficou conhecida como Brejos do Padres. (PANKARARU, Genildo. Entrevista. Entrevistador: Elvio Juanito Marques de Oliveira Júnior. Gurupi, 2017).

Neste processo de contato, os missionários jesuítas começaram a introduzir a língua portuguesa, forçosamente. Assim, os nativos tiveram que aprender a língua portuguesa, o que acarretou o esquecimento de muitas de suas palavras de origem. Como vemos na sequência do relato de Genildo Pankararu:

No início, bem no início, os Pankararu falavam Tupi Guarani, aí vieram os missionários e acabaram com tudo. Era assim: se você falasse na língua Tupi eles vinham e cortavam sua língua, porque a gente tinha que falar o Português, aí os Pankararu ficaram com medo e pararam de falar até acabar. Hoje poucos Pankararu

\footnotetext{
6 Brejo dos Padres é também referência ao nome de um pequeno vale de terras úmidas e muito férteis, localizado em pleno sertão pernambucano. Seu formato é alongado, semelhante a um anfiteatro, voltado para as margens do rio São Francisco (ARRUTI, 1996).
} 
falam a língua original. (PANKARARU, Genildo. Entrevista. Entrevistador: Elvio Juanito Marques de Oliveira Júnior. Gurupi, 2017).

Dessa forma, o português, sendo a principal língua falada hoje na etnia Pankararu, é resultado de séculos de invasões, que "envolve negros, colonizadores e vários povos indígenas (...)" (OLIVEIRA, 2016, p. 28).

Vale ressaltar que alguns membros mais velhos ainda falam o Tupi. Assim, outras formas de viver foram impostas, sem que eles pudessem ter, muitas vezes, qualquer tipo de escolha:

(...) os índios não puderam ter liberdade de escolha, de olhar o leque de opções e dizer: "nós queremos isso, nós queremos trocar aquilo". As relações foram assimétricas em termos de poder. Não houve diálogo. Houve imposição do colonizador (FREIRE, 2000, p. 13)

No mesmo trajeto histórico, Oliveira (2016) discorre que o pesquisador e antropólogo Dr. Carlos Estevão, em 1934, registrou a existência dos índios que viviam na Canabrava, hoje município de Tacaratu. "Foi feito um estudo que confirmou então a existência dos Pancaru (como era chamado antigamente)" (OLIVEIRA, 2016, p. 12). Além disso, uma grande seca atingiu as terras Pankararu no ano de 1939. "Por esta razão, aconteceu a primeira migração significativa desta etnia, com destino ao Estado do Mato Grosso, onde passaram a trabalhar na construção de estradas" (LIMA, 2008, p. 7). Em 1940, os Pankararu começaram a sair novamente de Pernambuco para procurar outras maneiras de sobreviver.

Estes dados sobre os Pankararu exemplificam e traduzem também as situações de como viviam outros povos indígenas do Nordeste. Tais situações em comum são reforçadas por João Pacheco de Oliveira (1998) como dois movimentos importantes: o primeiro (na metade do século XVII e nas primeiras décadas do XVIII) associado à atuação colonizadora das missões religiosas; e o segundo (no século XX e que segue atualmente) está ligado às imposições nos entendimentos de que a sociedade indígena teria um modo de vida próprio, individualizado, o que pode ter contribuído para o distanciamento da sociedade indígena de outras formas culturais. Como veremos nas discussões posteriores.

\section{Novos momentos: perseguições, organização e rituais}

Os Pankararu sofriam com mais perseguições - a partir de 1940 -, dessa vez de fazendeiros e posseiros que utilizavam da mão de obra dos indígenas e tornaram-se patrões desses nativos na produção de rapadura, na criação do gado e nas tarefas domésticas em Pernambuco (ARRUTI, 1996). No entanto, o que poderia parecer aos olhos dos não Pankararu como apenas exploração, era considerado por estes indígenas como uma 
relação de resistência possível, já que enquanto respeitavam e exerciam seus trabalhos, esperavam obter retorno, seja na alimentação ou na tranquilidade das aldeias (ATHIAS, 2002). E acabavam mantendo relações mais constantes, principalmente de parentesco, até para garantir suas sobrevivências.

Os conflitos dos Pankararu com os não indígenas, no Estado do Pernambuco, continuaram até 1984. O apaziguamento dessas relações conflituosas pode estar relacionado à demarcação da Terra Indígena Pankararu, que aconteceu em 1987, com 8.100 hectares homologados e que conta com 14 aldeias $^{7}$. Mais tarde, em 2004, uma nova porção é homologada (7.760 ha), sendo denominada de Terra Indígena Entre Serras (OLIVEIRA, 2016). No entanto, a demarcação das terras e os benefícios proporcionados por ela vieram um pouco tarde. As migrações já estavam intensificadas, com os Pankararu fugindo dos conflitos e buscando melhores condições de vida em outras regiões do país. Por outro lado, a demarcação ajudou os Pankararu a fortalecer sua cultura e rituais.

A organização social do povo Pankararu pode ser compreendida por no mínimo duas categorias amplas e notáveis, em que todas as famílias Pankararu encontram um lugar: as aldeias e os troncos ou "ramas" (ARRUTI, 1996; ATHIAS, 2002). A aldeia relaciona-se à organização local das famílias e dos laços de lealdade. Os troncos as separam em índios de "tronco velho", chamado por eles de "puros" e "autênticos"; e aqueles de um presente feito de gente "braiada", de "caboclos misturados" (ARRUTI, 1996). Essa organização "não implica em regras para os casamentos e os rituais nas aldeias", esclarece Genildo Pankararu. Vale ressaltar que outras formas de organização, não mencionadas pelos citados autores, podem estar relacionadas ao grupo indígena, especialmente fora do ambiente das aldeias.

Além disso, Genildo lembra que os principais rituais são o Toré e o Menino do Rancho, que estão interligados à invocação dos Encantados, às entidades religiosas ou "deuses dos Pankararu". Segundo Albuquerque, "os encantados são entidades sagradas que habitam na natureza, são atributos de Deus, elas são entidades vivas, já que são seres que não morreram, sendo entendidos como ancestrais dos Pankararu que se encantaram, ou seja, passaram para o plano espiritual (...)" (ALBUQUERQUE, 2011 , p. 29).

Ao lembrar do Toré, Genildo se emociona entre uma fala e outra:

Lá nas aldeias de Pernambuco temos vários rituais de danças como o Toré e Menino do rancho. E tem a corrida do umbu, que é tradicional... e vários outros. No Toré, nós dançamos e cantamos músicas tradicionais. E acontece para invocar os Encantados, que são nossos deuses, que trazem bênçãos, principalmente quando

\footnotetext{
${ }^{7}$ As 14 aldeias da Terra Indígena Pankararu são Saco dos Barros, Bem-querer, Caldeirão, Carrapateira, Caxiado, Tapera, Agreste, Espinheiro, Macaco, Barrocão, Serrinha, Logradouro, Barriguda e Brejo dos Padres, sendo esta última com maior população (OLIVEIRA, 2016).
} 
alguém está doente. Quando uma pessoa do coração puro e bom morre, ela não morre, ela passa a morar nas serras e vira um Encantado. Daí quando precisamos, realizamos os rituais como o Toré e o Menino do Rancho, fumando [campiô, um cachimbo em forma de cone], bebendo [garapa] e invocando, muitos vestidos de Praiás, com roupas de palha, mas ninguém pode saber quem são os Praiás. Essa é a parte forte, espiritual dentro da aldeia. Os Pankararu são muito espirituais. E se a pessoa receber a benção, a gente mata um carneiro macho ou um boi pra pagar a benção. Ainda quero levar isso pro Tocantins. (PANKARARU, Genildo. Entrevista. Entrevistador: Elvio Juanito Marques de Oliveira Júnior. Gurupi, 2017).

Assim, o Toré tem passos ritmados ao som de flauta e "exige muita concentração: só vestem a roupa aqueles 'puros de espírito', que não mantiveram relações sexuais há pelo menos três dias, e o nome do índio que veste a roupa é ocultado dos demais participantes" (FRANÇA, 2008, p. 20). Para Claudia Mura (2008, p.3), rituais como o Toré, “(...) revelam saberes, crenças e formas de transmiti-las que não podem ser enfocadas como se fossem o resultado de uma visão do mundo cristalizada e originária de um passado milenar, nem sequer uma recente 'invenção'”.

\section{Do sertão pernambucano às favelas de São Paulo:}

Como dito anteriormente, além das invasões e conflitos de terras, os nativos sofriam com a seca e, proporcionalmente, com a fome, como muitos outros nordestinos. A partir disso, começaram a migrar desde 1940 para a zona sul da cidade de São Paulo (FRANÇA, 2008), a exemplo de outros povos indígenas ${ }^{8}$. "Muitos Pankararu migraram para São Paulo (...) residindo [mais de 800 ] em uma favela (Real Parque/Morumbi) na capital paulista" (ATHIAS, 2002, p. 5). Além dessa favela, os Pankararu se espalharam pelos bairros Capão Redondo, Jardim Elba, Paraisópolis, Grajaú, Jardim Palmas, Sônia Maria e Jardim Irene (LIMA, 2008). Na primeira década do século XXI, o número de habitantes Pankararu em São Paulo já chegava a mais de 2.500 indivíduos (ATHIAS, 2002). A tese "Regime Imagético Pankararu" de Marcos Alexandre S. Albuquerque (2011, p.48) menciona essa população indígena, na Capital Paulista, como "o único grupo indígena migrante do nordeste que estava, efetivamente, organizado". Novamente Genildo nos conta essa história em seus relatos:

Não dava mais pra ficar no Pernambuco, na aldeia. Os Pankararu viviam em conflitos com o homem branco, que queriam nossas terras, não respeitava os índios. $\mathrm{E}$

\footnotetext{
${ }^{8}$ Na região metropolitana moram, além dos Pankararu, os Fulniô, os Xavante, os Xucuru, os Xucuru-Kariri e os Pankararé (GIANNECCHINI, 2005 apud LIMA, 2008.).
} 
nossos parentes estavam passando fome, não encontram emprego e fomos atrás de mais condições de vida em vários Estados. São Paulo era o principal destino. Hoje muitos vivem lá. (PANKARARU, Genildo. Entrevista. Entrevistador: Elvio Juanito Marques de Oliveira Júnior. Gurupi, 2017).

O crescente número de Pankararu em São Paulo pode estar ligado, também, segundo Lima (2008, p.7), a um caráter sistemático e familiar: "a cada núcleo familiar que se instalava, aumentava a possibilidade de que novos jovens percorressem este caminho". Entre outros fatores, segundo a autora, estão a busca por trabalho (e, assim, por conseguir recursos para sobrevivência), além de passeio e tratamento de doenças.

Ao saírem de ambientes nativos, em seus territórios indígenas do Nordeste, os Pankararu estariam diante de um "processo de reorganização social" ou "territorizalização" (OLIVEIRA, 1998), que implica, segundo ele, entre outras coisas, na reelaboração da cultura e da relação com o passado.

Embora São Paulo (SP) tenha se popularizado e se tornado um dos principais destinos dos Pankararu, não foi o único lugar escolhido por esses indígenas.

\section{O povo esquecido: fazendo história no antigo norte goiano}

O antigo norte de Goiás, hoje Tocantins, passou a ser também um dos lugares escolhidos pelos Pankararu para migração, por volta de 1945. Ainda no centro de Gurupi, Genildo Pankararu foi quem fez tal afirmativa:

Nós saímos de Pernambuco expulsos por fazendeiros, que invadiam nossas terras. Tinha muita fome também, por causa da seca e não tinha emprego, as aldeias estavam passando necessidades. E tínhamos que buscar como sobreviver. Alguns foram pra São Paulo e o que pouca gente sabe é que a gente veio pra Goiás, onde aqui hoje é o Tocantins. Ficamos sabendo que aqui tinha oportunidades, aí veio o primeiro, que era o tio Manoel, depois eu, depois vieram vários parentes. Estamos aqui até hoje, sobrevivendo dia após dia. (PANKARARU, Genildo. Entrevista. Entrevistador: Elvio Juanito Marques de Oliveira Júnior. Gurupi, 2017).

Esse relato de Genildo confirma ainda o que outros Pankararu já haviam dito durante as vivências e coletas de dados: o primeiro Pankararu a chegar ao Tocantins foi Manoel Marcelino Barros ou Manoel Pankararu, como era conhecido pela comunidade indígena. Veio para o Estado na década de 1940, morou nas cidades de Araguaçu, Gurupi, Cariri e, por último, em Figueirópolis, onde faleceu em 2011. 
Os relatos de sua vida estão até hoje guardados na memória de sua esposa Ana Barros, aposentada, 72 anos, moradora da pacata cidade de Figueirópolis (cerca de $6 \mathrm{mil}$ habitantes), na mesma casa da rua Amazonas, no centro, onde Manoel morou por mais de 30 anos. Na porta de sua casa, no final de uma tarde, com uma rua quase deserta, ela relatou, por meio de entrevista:

\begin{abstract}
Manoel saiu de Pernambuco pra trabalhar. Nasceu na aldeia Brejo dos Padres e foi para a cidade de Corumbá, lá no Mato Grosso, onde foi servir o Exército... isso por volta de 1941, aos 18 anos de idade. Depois de uns cinco anos foi pra Araguaçu, na época Goiás e hoje Tocantins, onde trabalhou na Polícia Militar. Lá teve uma mulher e três filhos, mas separou anos depois. Em 1965, ele muda pra Gurupi e onde nos conhecemos. Eu não sabia que estaria casando com um indígena (risos)... isso nunca me incomodou, mas incomodou várias pessoas. Moramos uma época em Cariri e, por último, passamos a morar aqui em Figueirópolis, desde 1976. Temos seis filhos.... (BARROS, Ana. Entrevista. Entrevistador: Elvio Juanito Marques de Oliveira Júnior. Figueirópolis-TO, 2017).
\end{abstract}

Esse relato comprova, entre outras coisas, o que havíamos citado na apresentação, a hibridização cultural não apenas no contato, mas nos relacionamentos afetuosos entre os Pankararu e os não indígenas, tal como o de Manoel Pankararu e Ana Barros (não indígena). Além disso, vêse nos relatos a existência de preconceitos e ideias equivocadas sobre os povos indígenas, que abordaremos mais a frente.

Ana Barros relata que, com o passar dos anos, vieram outros familiares ou parentes, como eles costumam se referir uns aos outros da mesma comunidade indígena:

Depois de Manoel, veio Genildo. Manoel queria tá perto dos seus parentes. Então Genildo formou família. Ele e Manoel foram os que mais lutaram pelos Pankararu. Ajudaram os que vinham de lá e brigavam com a Funai, Funasa e na Justiça pela terra e por ajuda pra esses índios viverem aqui. Não era fácil. Genildo continua aí com muitos outros Pankararu pela demarcação das terras. Era um sonho de Manoel ter essa terra demarcada, mas, nada até hoje. E torço pra que meus filhos, netos e bisnetos consigam preservar as culturas de alguma forma, que Manoel tanto sonhou. (BARROS, Ana. Entrevista. Entrevistador: Elvio Juanito Marques de Oliveira Júnior. Figueirópolis-TO, 2017).

Antes de adentrar ao tema da luta pela demarcação da terra indígena, descrevo a história pelo viés de Genildo Pankararu, sobrinho de 
Espaço Ameríndio

Manoel Pankararu. Ele veio para o Estado, em 1989, como relatado, por influência do tio e para buscar melhores condições de vida:

Muitos falam de povos nativos do Tocantins, mas nunca lembram dos Pankararu. Nós chegamos na década de 1940, meu tio Manoel estava aqui antes do Estado ser criado, então nós também somos nativos... Pra você vê, ele participou da primeira missa na construção de Palmas, viu o Estado crescer. Nem mesmo somos lembrados por nossa história. Eu vim pra cá graças a ele, que me ajudou muito. Vim pra tentar a vida aqui, mas não foi e não está sendo fácil. Somos do Pernambuco, mas somos também de São Paulo e do Tocantins. (PANKARARU, Genildo. Entrevista. Entrevistador: Elvio Juanito Marques de Oliveira Júnior. Gurupi, 2017).

O esquecimento é uma das palavras mais utilizadas pelos indígenas, principalmente ao relatarem suas histórias no Tocantins. Todavia, a história aqui narrada nunca foi aprofundada em pesquisas, livros ou reportagens jornalísticas. As instituições e estudiosos em antropologia, geografia ou história sempre mencionaram superficialmente a presença dos Pankararu no estado, seja para quantificar os povos indígenas do Tocantins, seja para mencioná-los nos "traços pluriculturais do estado" (SILVA, 2010), ou ainda em catálogos, livros, notícias ou portais institucionais. Tal como a citação do livro Tocantins: História e Geografia, do autor e professor Júnior Batista do Nascimento:

\begin{abstract}
A população indígena do Tocantins é composta pelas etnias: Apinajé, Xerente, Karajá, Krahô, Xambioá, Javaé e Krahô-Kanela, todas já reconhecidas e com terras demarcadas, além dos povos Pankararu, que estão em fase de reconhecimento e aguardando a demarcação de suas terras no município de Figueirópolis. (...) São originários do sertão de Pernambuco, aldeia Brejo dos Padres, e há mais de 30 anos migraram para o antigo norte goiano (NASCIMENTO, 2011, p. 87).
\end{abstract}

Os poucos relatos comprovam que os Pankararu são lembrados quantitativamente apenas para realçar a existência e não para enfatizar suas contribuições históricas e culturais para o Estado. Ao continuarmos adentrando à história desses indígenas, é importante realçar outros momentos dos Pankararu no Tocantins relatados por eles, como a luta pela federalização da universidade pública, hoje Universidade Federal do Tocantins (UFT), e pela implantação do Sistema de Cotas na mesma universidade. É o que Genildo Pankararu descreve nas lembranças de suas memórias: 
Anos depois que cheguei, eu logo corri pra fazer faculdade. Porque eu queria melhorar de vida. Lá em Pernambuco não estava fácil. Daí fui fazendo agronomia aos poucos em Gurupi, na época a gente recebia quase nada de ajuda da Funai. Eu tinha que matar aula pra vender artesanato, porque eu também tinha família pra criar. Quando eu estudava eu ganhei essa casa do meu sogro, em 2000, e passei a morar no centro de Gurupi, com minha esposa e dois filhos. Tive que ir me virando... Nesse tempo, eu e outros indígenas do Estado começamos a lutar pela federalização da Unitins, hoje UFT, e pelas Cotas para os índios. E conseguimos, vencemos, já que em 2003 foi a federalização e depois chegaram as cotas. Depois ainda construímos, com muita luta, a União dos Estudantes Indígenas do Tocantins - UNEIT. A gente tava lá, junto com outros índios. (PANKARARU, Genildo. Entrevista. Entrevistador: Elvio Juanito Marques de Oliveira Júnior. Gurupi, 2017).

A busca por seus direitos, por qualificação profissional e outras formas de sobrevivência comprova ainda o caráter dinâmico das identidades indígenas. Como afirma Silva:

esse indígena do passado não corresponde aos que transitam nas cidades, nos espaços públicos e universidades e que reivindicam demarcação de terras e questionam os grandes projetos de desenvolvimento que afetam diretamente sua sobrevivência e suas práticas tradicionais (SILVA, 2010, p. 159).

Dos mais de 70 anos da presença dos povos Pankararu no Tocantins, muitos deles foram marcados pela luta em prol da demarcação de terras, o que perpassa até os dias atuais, como narra e enfatiza Genildo:

Em 2004 entramos com um processo de demarcação de terra pra nós Pankararu. O Ministério Público até andou nos procurando, entrevistando, mas até agora nada. Vários índios de outras etnias aí conseguiram fácil a terra e nós nada, não sabemos em que pé tá. Estamos aí esperando, toda vida. Viver na cidade não é fácil pro um índio, pelo preconceito e pouca oportunidade que temos. E até hoje tá nessa toada. Atrás de terra, de demarcação, de melhorias. (PANKARARU, Genildo. Entrevista. Entrevistador: Elvio Juanito Marques de Oliveira Júnior. Gurupi, 2017). 
Espaço Ameríndio

\section{Identidades em transformação}

Neste período, dividido entre universidade, família e espera por demarcação das terras, Genildo relata as dificuldades que enfrentou juntamente com outros Pankararu que residem especialmente em Gurupi. Buscam sobreviver na cidade e, em paralelo a isso, convivem com as barreiras do preconceito:

Ninguém quer dar emprego pra um índio. A gente sofre muito preconceito. Falam assim: "E índio trabalha? Índio tem que ficar é na aldeia, não pode morar na cidade não". Como se a gente não tivesse capacidade. A gente que eu falo, eu e meus parentes Pankararu, primo e amigos, que vieram morar no Tocantins por causa de mim e do tio Manoel. E nós nos profissionalizamos, estudamos...ninguém quer saber disso. Mas não é fácil sobreviver na cidade. Eu vendo artesanato que a gente traz lá de Pernambuco, corro atrás de uma coisinha aqui, outra ali, pra sobreviver... Outros estão se virando por aí. (PANKARARU, Genildo. Entrevista. Entrevistador: Elvio Juanito Marques de Oliveira Júnior. Gurupi, 2017).

Ao buscarem o acesso ao mercado de trabalho estão sujeitos, quase sempre, a ocuparem condições inferiores ${ }^{9}$, incluindo várias formas de trabalho escravo (FRANÇA, 2008). Assim, ao procurar o mercado de trabalho "os índios são vistos como preguiçosos e propensos ao furto, sujos e ignorantes" (MELLATI, 1967 apud SILVA, 2010, p. 152). A sociedade, por sua vez, cria essas barreiras preconceituosas e racistas pelas ideias equivocadas construídas e reproduzidas desde o período colonial, especialmente aquela de que as culturas indígenas são atrasadas $^{10}$, sem levar em conta a compreensão do transito e das interações existentes entre outras formas culturais, congelando assim suas culturas (FREIRE, 2000) e desconsiderando que as identidades estão se transformando constantemente (HALL, 1992).

Assim, os Pankararu estão construindo suas próprias identidades, visto que toda identidade é construída a partir da negação de outra identidade (LÉVI-STRAUSS, 2012). Todavia, como pontua Sahlins (1997, p. 64), "não podemos subestimar o poder que os povos indígenas têm de integrar culturalmente as forças irresistíveis do sistema mundial". Ao falar em apropriação" ", estamos chamando a atenção para as transformações inerentes à vida e à cultura dos Pankararu, ao se mudarem para outras

\footnotetext{
9 “A situação é ainda pior para os índios que vivem em favelas, isso porque, em geral, quando estão nessa situação já não são considerados índios” (FRANÇA, 2008, p. 25)

10 “Os povos indígenas produziram saberes, ciências, arte refinada, literatura, poesia, música, religião. Suas culturas não são atrasadas como durante muito tempo pensaram os colonizadores e como ainda pensa muita gente ignorante" (FREIRE, 2000, p. 6)

11 "O que é enfatizado é um processo de partilha e apropriação em perspectivas multidirecionais. Uma perspectiva do contato que busca entender o que se designa por dimensões interativas e improvisadas dos encontros culturais" (GONÇALVES, 2010, p. 87).
} 
terras que não as suas, e transformarem esses novos lugares em seu novo lugar. Assim, esses indígenas não estariam perdendo suas tradições culturais, mas reinventando novas formas de viver, já que as identidades estão sempre em construção, como enfatiza Hall:

Assim, a identidade é realmente algo formado, ao longo do tempo, através de processos inconscientes, e não algo inato, existente na consciência no momento do nascimento. Ela permanece sempre incompleta, está sempre "em processo", sempre "sendo formada" (HALL, 2006, p. 38).

Mura (2008) chama atenção para este processo de construção identitária característica dos Pankararu. Segundo a autora, "torna-se de crucial importância analisar o processo de incorporação dos elementos de outras tradições e sua elaboração, em contínua transformação ampliada e modificada".

Em meio às transformações provocadas pelo tempo, os Pankararu vivem o paradoxo entre a manutenção de suas tradições culturais e as novas formas de viver e se relacionar nas grandes cidades. Para que ocorra a garantia de seu modo de vida, os Pankararu entendem que é necessário ter as terras devidamente demarcadas no Tocantins. É possível considerar que essa demarcação se tornou uma das maiores problemáticas para essa população indígena. Os Pankararu abriram um processo judicial em 2001 junto ao Ministério Público Federal, no Tocantins, para demarcação da terra ou reserva indígena Pankararu e aguardam desde então. Genildo Pankararu relatou que a ausência da terra dificulta as práticas rituais indígenas:

Como vamos fazer o toré e invocar os Encantados? Se a gente fizer aqui na rua, vão achar que é macumbaria, feitiçaria. E outra coisa, com a terra vamos ter mais união. Tem Pankararu espalhado pra todo canto, é aqui, é em Figueirópolis, Goiânia, Palmas... Estamos se perdendo... porque estamos buscando outras formas de viver e não é fácil. Estamos dentro dos costumes do homem branco, não temos um local pra expressar nossa cultura. Só temos mais controle sobre nossa cultura e sobre nosso povo quando temos terra. A nossa referência chama-se terra. (PANKARARU, Genildo. Entrevista. Entrevistador: Elvio Juanito Marques de Oliveira Júnior. Gurupi, 2017).

Os discursos anteriores enfatizados pelos indígenas retratam o enfraquecimento de algumas práticas culturais dos Pankararu, justamente pela ausência das terras. Isso ocasiona, ainda, com o passar do tempo, o risco do esquecimento, apagamento e silenciamento (BARTH, 1995) de certas formas culturais desses indígenas, especialmente dos 
existentes no Tocantins, visto que há novas experiências e práticas culturais, outras interações sociais e, assim, constantes transformações.

Ora, se ao invés de praticar seus costumes, os Pankararu dão acesso ao trabalho, educação, formas de alimentação, modos de vestir, conviver e viver em sociedade dos não indígenas, por exemplo, esses apagam e silenciam muitas de suas formas e expressões culturais. Este esquecimento é fortalecido ainda pelos não indígenas, que criam, socialmente, maneiras de exclusão ou não aceitação de práticas culturais indígenas, principalmente pela reafirmação da ideia equivocada de que esses povos são inferiores e devem se adaptar a outras práticas culturais que não sejam as suas.

O enfraquecimento das identidades Pankararu, segundo os relatos coletados, está ligado à ausência da terra indígena. Genildo questiona "Até quando isso?", como se tivesse falando para um todo e representando a fala dos mais de vinte e cinco Pankararu ${ }^{12}$ existentes nos centros urbanos do Tocantins:

Meus filhos foram tentar a vida em Palmas. Lá estudam... fazem um trabalho aqui, outro ali... estão se virando sozinhos. Estou pensando em voltar pra Pernambuco. Aqui em Gurupi o negócio não está fácil. A demarcação não saiu até hoje. Somos um povo sem terra no Estado do Tocantins, esquecidos... e olha que já somos mais de 25 Pankararu no Tocantins. Até quando isso? (PANKARARU, Genildo. Entrevista. Entrevistador: Elvio Juanito Marques de Oliveira Júnior. Gurupi, 2017).

Dessa forma, o território demarcado é um verdadeiro encontro das suas expressões culturais. É muito mais simbólico do que geográfico. Embora ocorra esse discurso de enfraquecimento das tradições Pankararu e inclusão de várias outras formas culturais, há na identidade Pankararu, como em todas as identidades, sinais diacríticos, ou seja, elementos simbólicos próprios. Barth (1976) ressalta que são as fronteiras que definem um determinado grupo.

(...) las fronteras étnicas son conservadas en cada caso por un conjunto de rasgos culturales. Por tanto, la persistencia de la unidad dependerá de la persistencia de estas diferencias culturales y su continuidad puede ser especificada por los cambios en la unidad producidos por cambios en las diferencias culturales que definen sus límites (BARTH, 1976, p. 48).

Ainda para Barth (1976), as fronteiras étnicas são mantidas, em cada caso, por um conjunto limitado de características culturais, que persistem apesar do contato interétnico e da interdependência. Além disso, os Pankararu do Tocantins, ao se identificarem como indígenas,

\footnotetext{
${ }^{12}$ Esses dados foram comprovados na fala de Genildo Pankararu. A Funai não respondeu sobre os mesmos até o término da coleta de dados e finalização desse artigo.
} 
Espaço Ameríndio

produzem "autoidentificação", que é uma das categorias definidas por Barth (1976); e, com isso, apresentam novas fronteiras étnicas que os diferem de outros grupos.

Autoidentificación. Ya sea que los individuos se consideren a sí mismos pertenecientes al grupo, al menos en algunos aspectos, o que así sean reconocidos por los demás miembros del grupo. No se debe olvidar el aspecto negativo de esta actitud, esto es, cuando un individuo no se considera perteneciente al grupo vecino. Esto puede ser muy importante en aquellos casos donde la identificación con el propio grupo no es particularmente firme. La identificación puede cambiar y el individuo puede considerar que pertenece al propio grupo sólo en determinadas situaciones, mientras que en otras puede estar en camino de identificarse con un grupo distinto. (BARTH, 1976, p. 48).

Esses sinais diacríticos, que diferem as expressões culturais dos Pankararu de outras tantas culturas, são justificados nos relatos de Arlete Barros, 51 anos, filha mais velha do casamento de Manoel Pankararu com Ana Barros, também residente de Figueirópolis. Ela concedeu detalhes sobre os costumes do seu pai que eram diferenciados de muitos não indígenas, como a confecção de artesanatos com sementes, a sua alimentação e crenças:

Meu pai sempre que podia ia lá em Pernambuco... na aldeia Brejo dos Padres. Trazia muitas sementes pra plantar e fazer artesanato. E passava o dia inteiro fazendo colares, pulseiras... Na casa dele tem um quintal cheinho de pinha e murici, que ele plantava. Ele saiu plantando aqui na cidade toda (risos). Não pra vender, mas pra comer mesmo. E eu sempre notei que as comidas que ele gostava eram bem típicas deles lá, muita mandioca, muita farinha, muita banana, frutas, peixes. E no dia do índio ele fazia cocar e saia de palha pras crianças, pra comemorar a data (risos). Era algo dele, era a cultura dele que era muito forte. E ele só não fazia os rituais, como toré, porque ele virou evangélico [protestante] e sempre falava que não gostava de fazer o ritual sozinho. Mas quando ia orar em casa, ele sentava debaixo de uma árvore e ficava sozinho. (BARROS, Arlete. Entrevista. Entrevistador: Elvio Juanito Marques de Oliveira Júnior. Figueirópolis-TO, 2017).

$O$ relato da indígena confirma justamente essa especificidade da identidade Pankararu, "ao aprofundar os processos de diferenciação" (GONÇALVES, 2010, p. 98). No entanto, essa fronteira étnica especifica dos Pankararu cria, socialmente, formas de exclusão, tal como o 
Espaço Ameríndio

preconceito, a dificuldade da demarcação das terras indígenas e, até mesmo, a imersão em outros grupos sociais.

Em poucas palavras, a cultura e a história dos Pankararu estão preservadas na memória desses indígenas, de acordo com os relatos apresentados. Contudo, eles aguardam a terra indígena para a prática dos seus rituais, além da garantia dos direitos aos povos tradicionais, como o acesso à terra e a constante luta pela igualdade e respeito. Os Pankararu, como afirma Mura (2008, p.16), "se encontram empenhados na constante elaboração da própria tradição cuja fundamentação é um universo rico de segredos, mistérios, enigmas e encantos".

\section{Considerações finais}

A história, assim como a etnografia, nunca chega ao fim, visto que é apenas o começo de uma jornada pelos caminhos dos povos indígenas. Com isso, poderão surgir, quiçá, novas perspectivas. Porquanto, é nos centros urbanos de Gurupi e Figueirópolis, sul do Tocantins, que os Pankararu fazem história e são resistentes ao tempo, aos preconceitos, ao desemprego, à marginalização dos centros urbanos e estão, infelizmente, diante do esquecimento da sociedade e do Estado tocantinense.

Ao mesmo tempo em que os Pankararu do Tocantins possuem uma diversidade cultural graças às novas apropriações que eles realizam, há sinais diacríticos (elementos simbólicos) presentes nos novos modos de viver desses indígenas que os difere dos grupos com os quais estão em contato. Isso nos faz compreender que a globalização e o capitalismo não estão destruindo ou homogeneizando as culturas, e sim gerando uma multiplicidade de novas formas culturais (SAHLINS, 1997).

Os povos indígenas, como os Pankararu, continuam a nos ensinar sobre diversidade, convivência, direitos, igualdade e, sobretudo, que as identidades continuam em plena transformação e resignificação, nunca estáticas como quer o senso comum. Só precisamos saber ouvi-los. 
Espaço Ameríndio

\section{Referências bibliográficas}

ALBUQUERQUE, Marcos Alexandre dos Santos. O Regime Imagético Pankararu. Tese submetida ao Programa de Pós-Graduação em Antropologia Social da Universidade Federal de Santa Catarina. Florianópolis, 2011.

ATHIAS, Renato. Espaço, Fecundidade e Reprodução entre os Pankararu. Ouro Preto - MG: Artigo publicado no XIII Encontro da Associação Brasileira de Estudos Populacionais, 2002.

ARRUTI, José Maurício Paiva Andion. O Reeencantamento do Mundo - Trama histórica e Arranjos Territoriais Pankararu. Rio de Janeiro: Dissertação do PPGAS do Museu Nacional. 1996.

BARTH, Fredrick. Los Grupos étnicos e sus fronteiras: la organização social de lãs diferenças culurales. México: Fondo de La Cultura Economica. 1976.

Etnicidade e o conceito de cultura. In: Antropolítica: Revista Contemporânea de Antropologia e Ciência Política. N.1. Niterói: EdUFF, 1995.

BURKE, Peter. Hibridismo cultural. São Leopoldo-RS: Ed. Unisinos. 2016.

FRANÇA, Vanessa Abdo. Da aldeia à favela: estudo da identidade de índios Pankararu no Real Parque. São Paulo - SP: Dissertação de Mestre em Psicologia Social pela PUC - São Paulo. 2008.

FREIRE, José Ribamar Bessa. Cinco Ideias equivocadas sobre os índios. In Revista do Centro de Estudos do Comportamento Humano (CENESCH). Manaus-Amazonas, No 01 - Setembro, 2000. P.17-33.

GONÇALVES, Marco Antonio. Zonas de Contato: quando "cultura" se torna um conceito nativo (Os índios na contemporaneidade). In: Traduzir o outro: Etnografia e Semelhança. Rio de Janeiro: 7 Letras, 2010.

HALL, Stuart. A identidade cultural na Pós-modernidade. Rio de Janeiro: DP\&A, 2006.

LÉVI-STRAUSS, Claude. Raça e história. In: Antropologia Estrutural 2. Rio de Janeiro: Cosac \& Naify, 2012.

LIMA, Carmen Lúcia Silva. Vivendo na metrópole: os Pankararu em São Paulo. Porto Seguro-BA: 26a Reunião Brasileira de Antropologia (RBA). 2008.

MURA, Cláudia. Circuitos rituais e fluxos interétnicos no Nordeste. $32^{\circ}$ Encontro Anual da Anpocs. 2008. Caxambu/MG.

NASCIMENTO, Júnior Batista do. Tocantins: história e geografia. Goiânia: 
Espaço Ameríndio

Bandeirante, $7^{\mathrm{a}}$ ed. 2011.

OLIVEIRA, Luís Antônio de. A língua Pankararu: puxando os fios da história. Belo Horizonte - MG: Trabalho de Conclusão de Curso de Línguas, Arte e Literaturas da Universidade Federal do Tocantins. 2016.

OLIVEIRA, João Pacheco. Uma etnologia dos "índios misturados"? Situação colonial, territorialização e fluxos culturais. Mana, vol. 4, n.1, Rio de Janeiro, 1998. Disponível em $<$ http://www.scielo.br/scielo.php?script=sci arttext\&pid=S010493131998000100003>. Acesso em 15 nov 2019.

SAHLINS, Marshall. O "pessimismo sentimental" e a experiência etnográfica: por que a cultura não é um objeto em vias de extinção (parte I). In: Revista Mana, ano, Vol. 3 (01):41-73, 1997.

SILVA, Reijane Pinheiro. O índio negado e o índio desejado: a "pacificação" dos indígenas na construção da identidade do Tocantins. Campo Grande-MS: Tellus, ano 10, n. 19, p.145-162, 2010.

\section{Entrevistas}

BARROS, Arlete. Entrevista. Entrevistador: Elvio Juanito Marques de Oliveira Júnior. Figueirópolis-TO, 2017.

BARROS, ANA. Entrevista. Entrevistador: Elvio Juanito Marques de Oliveira Júnior. Figueirópolis-TO, 2017.

PANKARARU, Genildo. Entrevista. Entrevistador: Elvio Juanito Marques de Oliveira Júnior. Gurupi, 2017. 